\title{
The influence of description of fire curves on the thermal and reliability response of steel structure
}

\author{
Katarzyna Kubicka ${ }^{1, *}$, Urszula Radon $^{1}$, and Waldemar Szaniec ${ }^{1}$ \\ ${ }^{1}$ Kielce University of Technology, Faculty of Civil Engineering and Architecture, Al. Tysiąclecia \\ Państwa Polskiego 7, Kielce 25-314, Poland
}

\begin{abstract}
The paper presents a proposal for the assessment of the reliability of statically determinate steel truss in the persistent and accidental (fire) design situation. The steel truss was modelled as series system from the reliability standpoint. The global Hasofer-Lind reliability index was employed, computed in successive time steps for the whole structure, not for individual elements. Fire analysis was carried out according to three different time-temperature curves-standard, hydrocarbon and external. Monitoring the reliability index in the successive minutes of the fire makes it possible to estimate the probability of the structure failure, and to decide whether the required safety level is maintained.
\end{abstract}

\section{Introduction}

Building structures should be designed and executed in such a way so that, under fire conditions, the bearing capacity could be ensured for an assumed period of time, required to enable safe evacuation of the users from the building. The knowledge of the theoretical basis of the behaviour of steel elements subjected to fire is presented in the monographs of: Maślak, Biegus, Kosiorek, Franssen, Vila Real, Kodur, Zaharia, Purkiss and Li $[2,6,7,8,12,16]$.

In recent years, some studies on the probabilistic evaluation of steel structures under fire conditions have been produced $[1,4,10,11,17]$. Those, however, concern the evaluation of simple elements, isolated from the whole of the structure. In the article, authors intend to analyse the structure as a whole.

\footnotetext{
*Corresponding author:ksuckert@tu.kielce.pl
} 


\section{Methods of analysis}

\subsection{Fire analysis of steel elements}

In the paper, three types of fire curves (standard, hydrocarbon and external) were adopted. The temperature of fire gases $\left(\theta_{g}\right)$ is described as follows [14]:

-standard fire curve:

$$
\theta_{g}=20+345 \log _{10}(8 t+1)
$$

-hydrocarbon fire curve:

$$
\theta_{g}=1080\left(1-0.325 e^{-0.167 t}-0.675 e^{-2.5 t}\right)+20
$$

-external fire curve:

$$
\theta_{g}=660\left(1-0.687 e^{-0.32 t}-0.313 e^{-3.8 t}\right)+20
$$

in equations 1.1-1.3 $\mathrm{t}$ is the time of fire duration. All mentioned temperature-time curves are shown in figure 1.

\section{Fire curves}

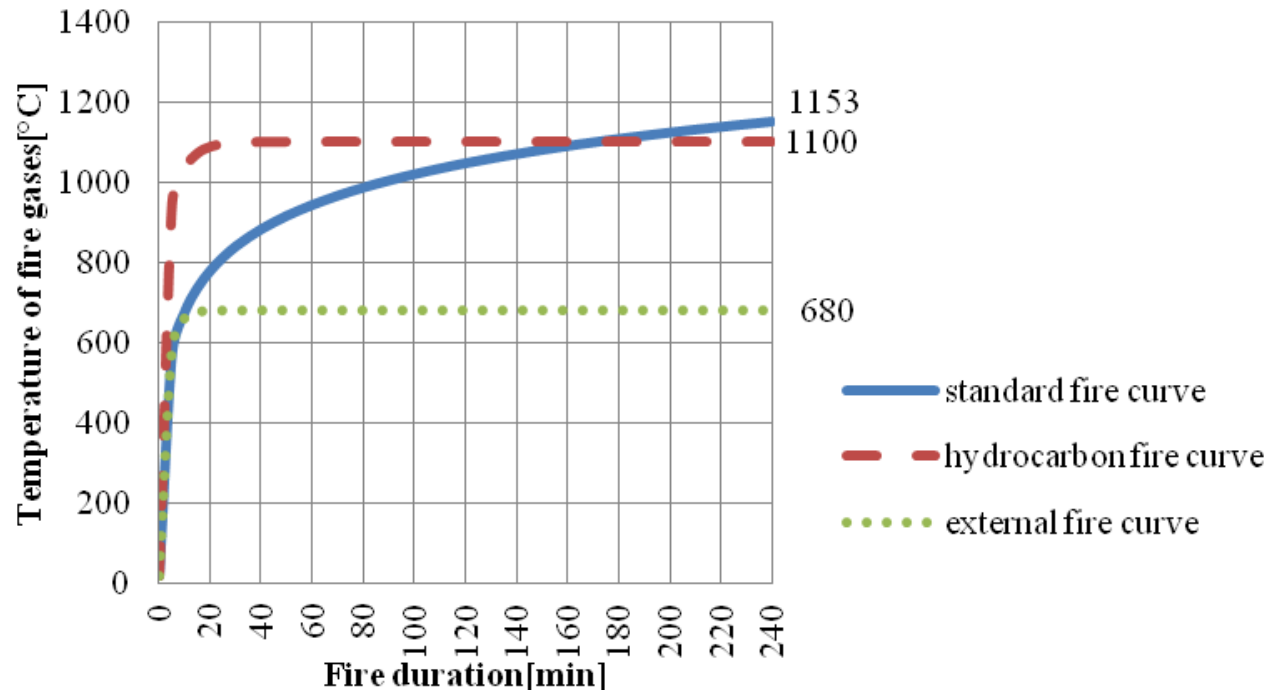

Fig. 1. Nominal temperature-time curves

When the temperature of fire gases is known, it is possible to determine the temperatures reached by individual bars and it is possible to calculate changes in steel mechanical properties that influence the bearing capacity.

When temperature distribution in the section is uniform, the temperature increment $\Delta \theta \mathrm{a}, \mathrm{t}$ of the insulated steel member in the time interval $\Delta \mathrm{t}$ is given by the following formula [15]: 


$$
\Delta \theta_{a, t}=\frac{\lambda_{p} A_{p} / V\left(\theta_{g, t}-\theta_{a, t}\right)}{d_{p} c_{a} \rho_{a}(1+\phi / 3)} \Delta t-\left(e^{\phi / 10}-1\right) \Delta \theta_{g, t}
$$

in addition:

$$
\phi=\frac{c_{p} \rho_{p}}{c_{a} \rho_{a}} d_{p} A_{p} / V
$$

where:

$\mathrm{A}_{\mathrm{p}} / \mathrm{V}$ - the section factor for steel members insulated by fire protection material, determined from Table 4.3 PN-EN 1993-1-2

$\mathrm{c}_{\mathrm{a}}$ - temperature-dependent specific heat of steel

$\mathrm{c}_{\mathrm{p}}$ - temperature-independent specific heat of the fire protection material

$\mathrm{d}_{\mathrm{p}}$ - the thickness of the fire protection material

$\Delta \mathrm{t}$ - the time interval (not greater than $30 \mathrm{~s}$ )

$\theta_{\mathrm{a}, \mathrm{t}^{-}}$the steel temperature at time $\mathrm{t}$

$\theta_{\mathrm{g}, \mathrm{t}^{-}}$the ambient gas temperature at time $\mathrm{t}$

$\Delta \theta_{\mathrm{g}, \mathrm{t}^{-}}$the increase in the ambient gas temperature in the time interval $\Delta \mathrm{t}$

$\lambda_{\mathrm{p}}$ - the thermal conductivity of the fire protection material

$\rho_{\mathrm{a}}$ - the unit mass of steel

$\rho_{\mathrm{p}}$ - the unit mass of the fire protection material

The design resistance at the member uniform temperature $\theta$ is given by the appropriate formulas in PN-EN 1993-1-2 [14].

\subsection{Reliability analysis of the system}

System-reliability analysis concerns the formulation of the limit state and calculation of the failure probability when the structure has more ways of failing. Mathematically we encounter system reliability analysis if the limit-state surface is composed by more pieces that generally intersect pairwise in sets of singular points, which are points at which the limit-state surface is not differentiable. Each of these pieces will usually be a part of a limitstate surface for a specific global failure mode or for a local failure. We can distinguish three main models of reliability system: series, parallel and mixed. The most common example of series system is a statically determinate structure. A series system is also denoted as a "weakest link" system. The reliability of structures, the static scheme of which is compliant with the series system, is computed according to the formula [5]:

$$
R=\prod_{i=1}^{n} R_{i}=R_{1} R_{2} \ldots R_{n}
$$

The parallel system is appropriate for some structures that are statically indeterminate. In the parallel system, the structure remains reliable as long as at least one element is reliable. The reliability of the parallel system is computed as follows [4]:

$$
R=1-\prod_{j=1}^{m}\left(1-R_{j}\right)
$$

A majority of statically indeterminate structures is in line with mixed systems. The two basic systems are parallel-series and series-parallel. In real structures, however, mixed systems are usually more complicated. 


\section{Results and discussion}

The presented method combines the fire and reliability analysis. The fire analysis was carried out according to the method described in $[6,7,13,14]$. The temperatures of fire gases and elements were calculated in the deterministic way. The analysis was carried out for the truss presented in figure 2. The profiles of elements and the effect of actions are shown in figure 2, where (-) means compression. All elements were assumed to be made from S235 steel. The structure was loaded by dead weight of layered roof plate $(0.094 \mathrm{kN} / \mathrm{m} 2)$ and by the snow $(0.72 \mathrm{kN} / \mathrm{m} 2$-second snow zone $)$. The whole load was converted to concentrated forces in the nodes.

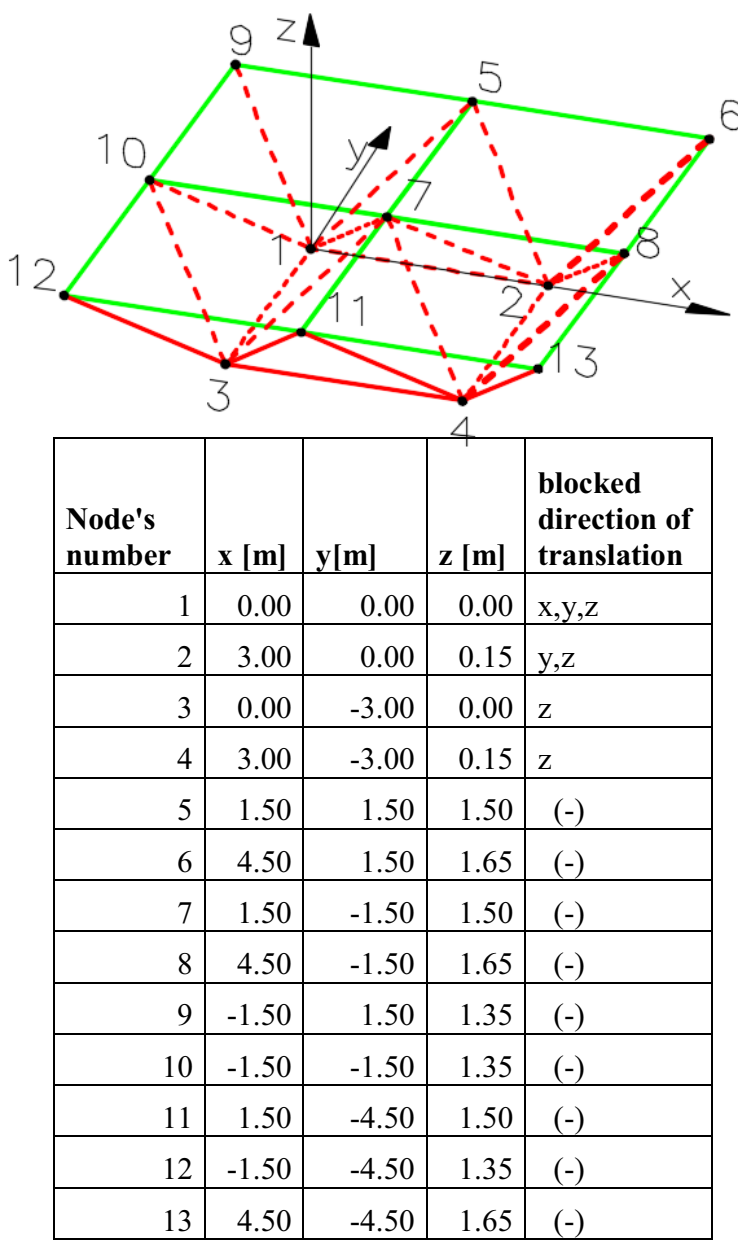

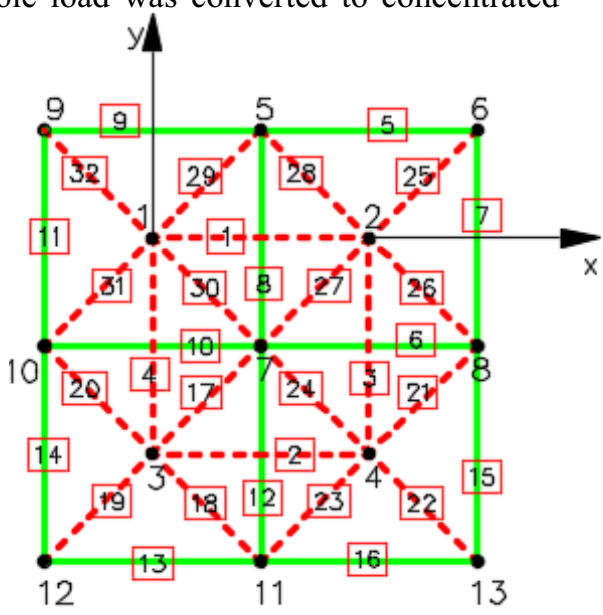

\begin{tabular}{|c|l|c|}
\hline $\begin{array}{l}\text { Element's } \\
\text { number }\end{array}$ & Profile & $\begin{array}{l}\text { Effect of } \\
\text { actions [kN] }\end{array}$ \\
\hline $1-4$ & CHS 20x3.2 & -0.02 \\
\hline $5,7,9,11,13-16$ & CHS 20x3.2 & 2.00 \\
\hline $6,8,10,12$ & CHS 20x3.2 & 3.98 \\
\hline 17,30 & CHS 30x3.2 & -3.42 \\
\hline $18,21,26,29$ & CHS 30x3.2 & -3.44 \\
\hline 19,32 & CHS 30x3.2 & -3.35 \\
\hline $20,23,28,31$ & CHS 30x3.2 & -3.33 \\
\hline 22,25 & CHS 30x3.2 & -3.46 \\
\hline 24,27 & CHS 30x3.2 & -3.32 \\
\hline
\end{tabular}

Fig. 2. Analyzed space steel truss

The thermal analysis was carried out for insulated structure. All the elements were assumed to be heated from each side. Three types of fire curves was analyzed: standard, hydrocarbon and external ones. Spray-applied vermiculite with cement with the thickness of $3 \mathrm{~cm}$ was assumed as an insulation. This material is characterized by the following parameters: density $\rho p=550 \mathrm{~kg} / \mathrm{m} 3$. specific heat $\mathrm{cp}=1100 \mathrm{~J} /(\mathrm{kgK})$. thermal conductivity $\lambda p=0.2 \mathrm{~W} /(\mathrm{mK})$. The results of thermal analysis-temperature of fire gases and temperature 
of steel elements according to different fire curves are shown in the figure 3. As whole elements have the same thickness they heat up in the same degree. According to Eurocode section factor for circular hollow section can be calculated as $1 / d$, where $d$ is thickness of section.

\section{Temperature of steel elements}

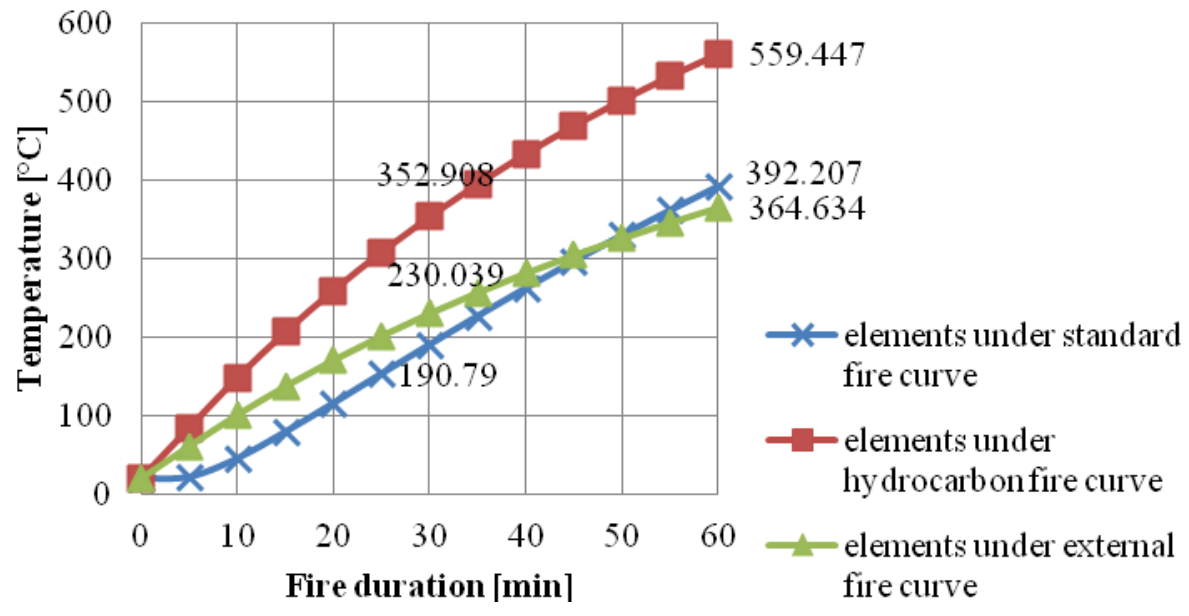

Fig. 3. Temperature of steel elements according to different types of fire curves

In the next part of analysis, for each step: 0, 5, 10, 15, 20, 25 and 30 minutes, the reliability analysis was carried out according to method presented in [9]. The influence of randomness was taken into consideration in the bearing capacity and the effect of actions. For both values, appropriate values of standard deviations, which are shown in the following table, was assumed.

Table 1. Random variables and their characteristics for the reliability analysis

\begin{tabular}{|l|l|l|}
\hline Random variable & Coefficient of variation [10,2] & Standard deviation \\
\hline $\begin{array}{l}\text { Effect of action for } \mathrm{i}^{\text {th }} \text { element } \\
\left(\mathrm{E}_{\mathrm{i}}\right)\end{array}$ & $v_{E}=0.06$ & $\sigma_{E}=0.06 \cdot E_{i}$ \\
\hline Yield strength (f $\mathrm{y}$ ) & $v_{f_{y}}=0.08$ & $\sigma_{f_{y}}=0.08 \cdot f_{y}$ \\
\hline Area of cross-section (A) & $v_{A}=0.06$ & $\sigma_{A}=0.06 \cdot A$ \\
\hline Bearing capacity (N) & $v_{N}=\sqrt{v_{f_{y}}^{2}+v_{f_{y}}^{2} \cdot v_{A}^{2}+v_{A}^{2}}=0.1$ & $\sigma_{N}=0.1 \cdot N_{i}$ \\
\hline
\end{tabular}

The entrance data were the mean values of the effect of actions and the bearing capacity, which was calculated according to [14]. Then, the reliability for each element of the structure was calculated. The structure has statically determinate scheme and corresponds to the series system, consequently, the failure of any element (1-32) results in the failure of the whole structure. The reliability of the structure (R) is calculated according to equation (5), particularly:

$$
R=\prod_{i=1}^{32} R_{i}
$$


The calculation according to method described in chapter 2 was carry out in Mathematica program. The results of the reliability analysis are presented in Fig. 4. The required value of the reliability index $(\beta)$ was assumed, according to [10], to equal 1.34. Dotted lines indicates the reliability indexes for the weakest elements (members 22 and 25), solid lines corresponds to the whole structure reliability.

\section{Reliability index}

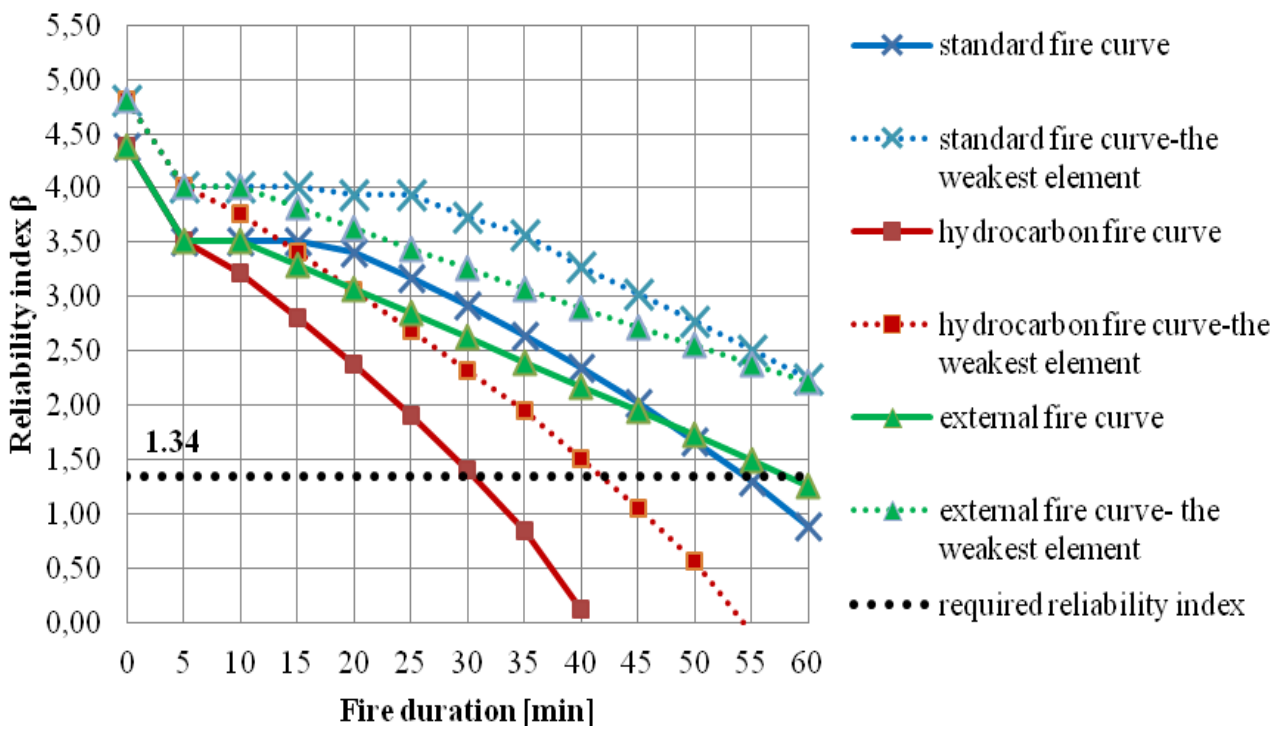

Fig. 4. Monitoring the reliability index in successive minutes of the fire

The application of the standard fire curve or the external fire curve made it possible to reach R45 fire resistance class. For the hydrocarbon curve, the reliability index falls below the required one after 30 minutes of fire duration. Additionally, in this case, the index drops below zero beyond the 40th minute.

\section{Conclusions}

This paper provided an analysis of a statically determinate spatial steel structure subjected to the action of fire. The first step involved the structure thermal response. The other step included the reliability analysis conducted using the Hasofer-Lind reliability index. Three types of nominal fire curves given in the Eurocode were taken into considerations. When the standard and external fire curves were applied, similar results of both the thermal and reliability analyses were obtained. However, with the hydrocarbon fire curve much more rapid increase in the temperature of the elements was found (Fig.3). That resulted in earlier decrease in the values of the mechanical properties of the materials, namely Young's modulus of elasticity and yield strength. Consequently, a very fast decrease in the reliability index was observed (Fig.4).

Using the standard fire curve or the external fire curve, R45 fire resistance class was achieved, whereas with the hydrocarbon fire curve, that was R30 fire resistance class. The fact illustrates the importance of appropriate curve selection which needs to account primarily for the use of a given object and the types of materials stored in it. If the ignition 
source are flammable substances, the hydrocarbon fire curve should be applied. In such a case, the use of the standard fire curve leads to the attainment of overestimated fire resistance class.

The reliability analysis conducted for the study shows a well-known and frequently reported effect of the static deterioration of the structure [3]. It is observed in statically determinate structures in which their reliability is computed in series system. In that case the reliability of a single element is much higher than reliability of the whole structure (Fig.4). That may raise doubts as to the correctness of Eurocode approach, in which individual elements are considered when dimensioning the structure in relation to the ultimate limit state. Structural design which utilizes the ultimate limit state method with partial safety factors, without taking into account the global reliability may lead to errors in evaluating the reliability of a given building structure. In the literature, the probabilistic measure of safety for the fire conditions is the minimum safety factor computed for the main structural elements at the ultimate limit state.

To sum up, it can be concluded that the system reliability analysis can be successfully combined with the fire analysis. For statically determinate structures, the determination of the reliability index with this method offers an option that is simple, and provides an alternative to traditional design methods.

\section{References}

1. D. K. Banarjee, Fire Safety Journal, 61, 65 (2013)

2. A. Biegus, Design of steel structures according to Eurocode 3. Fire safety of steel structures (Lectures in Polish) (Wrocław, 2013)

3. A. Biegus. Probabilistic analysis of steel structures (in Polish) (Polish Scientific Publishers PWN, Warszawa-Wrocław, 1999)

4. Q. Guo, K. Shi, Z. Jia., A. E. Jeffers, Fire Technology, 49, 793 (2013)

5. M. Gwóźdź, A. Machowski, The selected studies and calculations of building structures by probabilistic methods (in Polish) (Politechnika Krakowska, Kraków, 2011)

6. J. M. Franssen, V. Kodur, R. Zaharia, Designing steel structures for fire safety (CRC Press, Taylor and Francis Group, Boca Raton, London, 2009)

7. J. M. Franssen, P. Vila Real, Fire design of steel structures. Eurocode 1: Actions on structures. Part 1-2-General actions-Actions on structures exposed to fire. Eurocode 3: Design of steel structures. Part 1-2 General rules - Structural fire design (Ernst\&Sohn, 2012)

8. M. Kosiorek, Fire resistance of building structures (Arkady, Warszawa, 1988) (in Polish)

9. K. Kubicka, U. Radoń, ACE, 4, 141 (2015)

10. M. Maślak, Eight International Conference on Advances in Steel Structures Lisbon, Portugal, July 22-24 (2015)

11. M. Maślak, Metal structures: ZK 2014: Scientific-Technical Conference: short papers: Kielce-Suchedniów, July 2014 (2014)

12. M. Maślak, The fire durability of steel bar structures (Politechnika Krakowska, Kraków, 2008) (in Polish)

13. PN-EN 1991-1-2. Eurocode 1: Actions on structures - Part 1-2: General actions Actions on structures expose to fire. 
14. PN-EN 1993-1-1. Eurocode 3:Design of steel structures-Part 1-1: General rules and rules for buildings.

15. PN-EN 1993-1-2. Eurocode 3: Design of steel structures-Part 1-2: General rulesStructural fire design

16. J. A. Purkiss, L. Y. Li, Fire Safety Engineering Design of Structures (CRC Press, Taylor and Francis Group, Boca Raton, London, New York, 2014)

17. Ch. Zhang, G.-Q. Li, Y.-Ch. Wang, Structural safety 50, 16 (2014) 